\title{
Importa a naturalizaçäo do pae a do filho menor?
}

\author{
(Ao eminente mestre o Exmo. Snr. Conde \\ de Affonso Celso).
}

1) Esta questão tem sido resolvida diversamente pelos varios internacionalistas, o que é muito commum na sciencia em que surgiu, mas, além disso, tem tido, em diversas épocas, uma mesma solução dos escriptores coevos, como observa Rodrigo Octavio (Dr. Int. Pr. p. 45). Rodrigo Octavio entende que, no recebimento por parte dos juristas brasileiros do effeito collectivo da naturalização actuou a idéa da necessidade da coherencia com os principios geraes do Direito Internacional Europeu, o que quer dizer que, acceito o principio do jus sanguinis para se determinar a origem do individuo, deve-se adoptar a do effeito collectivo da naturalização, pois ambos os institutos nascem do interesse social reconhecido de não terem os membros de uma familia mais do que uma nacionalidade.

Anticipando o que vou desenvolver abaixo (n. ${ }^{\circ}$ 9), lembrarei que o eminente internacionalista Zeballos funda-se no rigor com que foi estabelecido o patrio poder na Argentina para solver a questão de que estou a occuparme, dando-lhe resposta contrária á que lhe dou no presente estudo. Eis as proprias palavras do grande jurista: "Le code civil argentin a organisé la puissance paternelle sous une forme rigoureusement autoritaire. L'incapacité de l'enfant mineur est complète. Le père le represente pour tous ses actes il agit pour lui même s'ils affectent les biens et les intérêts matériels du mineur." (Journal de Dr. int. de Clunet, T. 45, pag. 34). E' ésta a razão de decidir do illustre Professor, e com ella me occuparei linhas abaixo (n. 9 ). 
Não posso compartir a opinião do Tribunal ingles que, segundo Foote, deixou essa questão indecisa, por julgal-a summamente difficil: "The Court of Appeal, in the case cited, left this question unanswered, as one of great difficulty". E' certo que, como nota o mesmo escriptor, na letra da lei inglesa, sería extremamente difficil (exceedingly difficult) achar a solução do caso, mas, em tal hypothese, poderiam os juizes recorrer aos principios scientificos, que, a meu ver, dão meios de resolver a dúvida, comquanto, como diz o conhecido escriptor, haja desaccordo entre os luminares da Inglaterra (A Concise Treatise, p. 18, nota b).

2) Pelo que fica exposto, evidente se torna quão vantajoso será, para bom estudo da questão, examinar as vicissitudes por que tem passado a idéa de naturalização. A naturalização foi outrora um acto raro e isolado, de que não se occupavam os escriptores de Direito Civil Internacional, observa Laurent, ao passo que modernamente ella occupa logar preeminente em todas as obras sobre ésta sciencia. Era um favor do rei: "La naturalisation s'opérait autrefois par lettres du prince, accordées en grande chancellerie et enregistrées dans les cours souveraines: on les appelait lettres de naturalité" (Dalloz).

No mesmo sentido expõe Woolsey, que nos dá um optimo resumo do modo por que foi regulamentado este instituto nos varios paizes: "In England, formerly, an alien could cease to be such only in one of two ways, the first of which was by letters patent of the crown constituing him a denizen, in which status could purchase and devise landes, but receive no capacity of holding political trusts, and was not altogether free from burdens resting on aliens. The second way was naturalization by act of parliament, which placed the person concerned in a slightly superior status to that of a denizen, yet did not qualify him to hold political trusts". Ahi temos a mera concessão de direitos civis, e não do que os romanos denominavam 
jus honorum e jus suffragii. Razão pois tem Dalloz quando lembra, citando Denizart, que a naturalização não conferia "que la jouissance des droits civils,". Este systema perdurou até a transformação de idéas nos Estados Unidos da America, e Laurent fixa como tendo sido o anno de 1789 o em que se deu essa mudança na opinião dos juristas e dos legisladores. Este systema é por Laurent denominado o velho, o antigo (l'ancien système, le vieux système), em opposição ao outro, ao moderno a que elle julga dever attribuir o nome de americano. Succedeu, com effeito, ter sido nos Estados Unidos pela primeira vez acceito e proclamado, sendo depois recebido com muitos gabos pela França em 1790 e nos annos seguintes, como referem Laurent, Dalloz e outros juristas. Mas é de notar que do antigo systema restam vestigios, e que, segundo Laurent, é elle que domina na Belgica. O segundo systema, chamado americano pelo grande mestre belga, poderia tambem ser caracterizado pela denominação de legal, pois, por elle, se tornou a naturalização um direito que pode ser reclamado por quantos estrangeiros cumpram as prescripções legaes: passou pois de favor do rei, a direito consagrado na lei do paiz. De fóra parte os excessos da revolução francesa, mistura de Direito tradicional, Direito revolucionario e sentimentalismo republicano, tem sido o systema americano o que tem prevalecido desde 1789, em quasi todas as nações cultas. Incidentemente direi não me parecer fundado o escrupulo de Rodrigo Octavio em considerar naturalização a concessão feita pela Constituição brasileira de 1889 (aliás acompanhando a do Imperio), escrupulo revelado pelo notavel jurista patrio ao dar-lhe o nome de nacionalização (p. 32).

$\mathrm{Ha}$ ahi verdadeira naturalização por força da lei, e é a lei o elemento principal, ou antes o fundamental de toda naturalização modernamente. Naturalização foi sempre considerada a concedida pela Assembléa Francesa ao cidadão americano Franklin e ao allemão Klopstock. 
Oppenheim entende que, em tal caso, do mesmo modo que em muitos outros, ha naturalização, tomado o termo no sentido lato (naturalization in the wider sense of the term), dando-se então a mudança de nacionalidade ipso facto, ao passo que, quando obtida pelos meios legaes ordinarios, é a naturalização no sentido restricto do termo (naturalization in the narrower sense of the term). Hall (pag. 565) e Lafayette (138) consideram como sendo naturalização collectiva a resultante de conquista. Importantissimo é, para complemento dessas idéas propedeuticas, fixar que a naturalização, em suas particularidades, é regida pela lei interna, e não pelo Direito Internacional: "Internacional Law does not provide any such rules for such reception, but it recognises the natural competence of every state as a Sovereign to increase its population through naturalization although a State might by its Municipal Law be prevented from making use of this natural competence (Oppenheim). Mais claro ainda é Halleck (Elements of International Law, C. $29, \S 4) "$ It must be remembered, that although International Law recognizes the right of one State to naturalize or adopt the subjects of an other, it is not in virtue of this public law that such citizen is

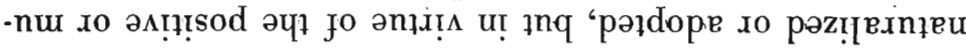
nicipal Law of the country, which naturalizes or adopts them".

Não é precisamente ésta a opinião de Davis, pois este considera a lei interna, neste assumpto como sendo suppletiva da externa: "The law of nations, which in this regard is supplemented by the municipal law" (The Elements, pag. 136).

3) Não é sem motivo que insisto sobre tal assumpto. Alexandre Alvarez, em sua monographia sobre o Direito Internacional Americano, observa com muita razão que os principios reguladores da nacionalidade são na America muito diversos dos acceitos na Europa, e que os publicistas europeus não fazem a distincção entre o que pertence 
ao Direito Interno e o que toca ás leis internaciónaes. Ora a. naturalização, capitulo da matéria de nacionalidade, effectivamente é concebida na America por modo muito differente do que, o é na velha Europa, e para isto não deixa de concorrer a diversidade dos interesses.

Explica Despagnet que, comquanto os ingleses e americanos sustentem, em sua maioria, que ha um Direito Internacional, comtudo consideram soberana a lei territorial, e só lhe abrem excepçôes, em caso de conflicto, fundadas na comitas gentium. Attribue isto ao genio da raça anglo saxonia. Parece-me mais natural attribuir a serem outras as condições de vida ou as necessidades na Inglaterra, e ainda muito mais differentes das européas, as americans, como optimamente provou o eminente mestre Zeballos (Journal de Dr. Int. de Clunet, T. 45, pag. 21). No fim deste trabalho, mostrarei quaes as concessões, que, segundo o mesmo internacionalista, têm feito os europeus aos americanos em matéria de naturalização, aliás acudindo aos seus proprios interesses, procurando as vantagens para a vida européa, e recusando taes concessões quando ellas lhes são totalmente desfavoraveis. Minha opinião é a de que a nacionalidade é definida pelo Direito Interno, chamado Municipal pela escola algo americana, mas que (contra a escola anglo americana) cumpre que a lei territorial se conforme com os principios geraes do Direito Internacional. E' á lei interna que compete dizer quaes os individuos no gozo dos direitos civis e politicos. Estou porém de accôrdo com Alvarez não só quanto a pertencer a matéria ao Direito Interno, mas tambem quanto a dever se dar particular attenção ao facto dos interesses americanos (abandonada a idéa da immutabilidade e universalidade do Direito Natural), para se attribuir á lei interna o poder de determinar as condiçóes necessarias para que as pessoas possam gozar da proteç̧ão juridica do paiz, e neste ponto é que julgo incompleta a escola européa contimental. 
Darei dois exemplos. Reconhecido que é inconveniente para um paiz ter cidadãos que se mantêm ligados a outro pelos mesmos laços de submissão, ou noutros termos, acceitar por naturalização individuo que ficará com uma dúpla nacionalidade, ou subdito mixto (Oppenheim $\S 310$ ), deve o Estado, em suas prescripçốes sobre o modo de alcançar a cidadania, determinar a exigencia de que o supplicante prove haver renunciado á cidadania da patria que abandona, ou adoptar outra medida para evitar este mal. Esta renuncia aos direitos que importa em verdadeira desnacionalização é admittida por alguns Estados entre os quaes se acha a Allemanha (Oppenheim $\$ 302)$. Direi que, entre os outros remedios contra o inconvenientes da dupla nacionalidade, são celebres os indicados nas 6 regras de Veneza formuladas em 1896. Lembrarei que a dupla nacionalidade nem sempre provém da naturalização. Emfim, para tornar bem claro o exemplo que acaba de ser dado, farei sentir que a dupla nacionalidade differe da fidelidade á patria deixada, instituto conhecido pela sua denominação inglesa allegiance (Pimenta Bueno, Dir. Int., n. ${ }^{\circ} 57$ ). Um outro exemplo pode ser tirado de um facto occorrido na Prussia. Em consequencia da annexação de Frankfort á Prussia, alguns jovens, com o intento de evitarem a conscripção das leis prussianas, naturalizaram-se suissos, e foram morar em Frankfort: "The prussian government expelled them, and the Swiss government admitted that its conduct was fully,justified" (Hall, pag. 237). Embora não se tracte, no caso; de naturalização, mas de saber quaes os individuos que podem permanecer num paiz, e quaes devem delle ser expulsos, vemos que a expulsão, na especie que acaba de ser referida, foi a consequencia de uma mudança de patria, e que foi pela naturalização em paiz estrangeiro que os antigos subditos prussianos deixaram de ter direito de continuar a morar em Frankfort, por uma lei prussiana ou de Direito Publico Interno, mas inspirada nos princi- 
pios geraes de Direito das Gentes, pois a Suissa não podia concorrer para se fraudar uma lei da Prussia.

A Suissa não foi ouvida, mas unicamente achou que o acto era justificavel e pensar doutro modo seria querer a subversão da sociedade civil pelo desrespeito á lei. Como se vê, ha ahi uma verdadeira privação da nacionalidade, uma desnaturalização (Mello Freire, I. L. 2, T. 2 \& 12), deprivation, como dizem os internacionalistas ingleses (Oppenheim § 302), objecto tambem das leis internas (Municipal Law), medida acceita com caracter geral em Portugal, Hespanha, Bulgaria, Grecia, Italia e Hollanda, no caso de entrar um seu subdito no serviço militar estrangeiro sem licença do seu soberano. Medidas tambem estabelecidas pelo Direito Interno são as relativas aos individuos que ficam sem patria, os heimathlos (Oppenheim $\S \S 311$ a 313). Bom é referir, ainda que com remotissima relação com a these que discutimos, terem essas medidas sobre privação de vantagens do nacional caracter, não raro, de penas. Foi o que succedeu com os rapazes de Frankfort, é o que acontece com os franceses que não attenderam á chamada por occasião da actual conflagração, os quaes ficaram privados de muitos favores que a patria dá a qualquer individuo, a qualquer estrangeiro, como, por exemplo, recorrer aos tribunaes franceses. Demais tenho me occupado, parece, da competencia do Estado para legislar sobre a naturalização, e sobre quem seja havido por nacional no paiz, e creio que, feita a Alexandre Alvarez a contestação de que ha um limite nos principios geraes á soberania dos Estados quando firmam regras sobre acquisição e a perda da nacionalidade, posso acceitar a these que elle com rara concisão firmou: "Le domaine du droit interne, en matière de nationalité, est facile à determiner. Chaque Etat statue souverainement dans les limites de son territoire sur l'acquisition et la perte de nationalité". (Le Dr. Int. Am. pag. 292). Fica assim bem claro que, em minha opinião, cabe ao Estado 
em suas leis internas firmar quaes as condições para a acquisição e para a perda da nacionalidade, mas respeitando os principios do Direito das Gentes, os interesses dos demais povos, ainda que seja verdade que esses interesses devem hoje ser apreciados de modo mais elevado, attendendo-se á entrada da America no concerto das nações.

5) Passo agora a ver o que se deu em relação á nossa patria, e terei de examinar o Direito Portugues, comquanto muito diffira do nosso pelo motivo que acabo de expor, qual a diversidade entre os interesses americanos e os do Continente Europeu. Embora houvesse exemplos de naturalização collectiva, como diz Despagnet (Dr. Int. Pr., n. ${ }^{\circ} 140$, pag. 439), foi no Reino sempre medida de caracter de favor a naturalização. 'A matéria era regida pela 0 . L. 2, T. 55 , e está muito bem compéndiada por Mello Freire. Diz o grande civilista: "Cives nascuntur augt fiunt. Nascuntur ex civibus nostris, fiunt domicilio et habitatione.". (Inst., L. 2, T. 2, § 1). A these do magno' sacerdote das letras juridicas portuguesas só pode ser acceita com a explicação dada no $\S 5$ : “Domicilio et habitatione perigrini filius civis et indigena jure nostro efficitur, si loco aliquo per decennium continuum illius pater fuerit commoratus, ibidemque sedes animo perpetuo permanendi posuerit". Sim: é pela circumstancia de ter domicilio e bens no Reino durante dez annos que os filhos de tal pessoa se tornam naturaes de Portugal si nascidos no Reino, conforme os clarissimos termos da O. L. 2 T. $55 \S 1$, occorrendo ainda a particularidade de não se tornar cidadão portugues o pae domiciliado "por qualquer tempo que seja". Este titulo, como se vê, em uma nota de Candido Mendes, fundada em asserto de Monsenhor Gordo, foi, parece, tirado de uma lei de 156.5, e nelle a naturalização propriamente não apparece, mas apenas a lei define que pessoas devem ser tidas por na. turaes de Portugal, quem deveria ser julgado subdito portugues, como hoje dizemos. 
Nas notas ao $\$ 29$ de seu Direito Civil, menciona B. Carneiro o alv. de 8 de Junho de 1433, prohibindo fossem passadas cartas de naturalização pelo incommodo aos naturaes resultante das isenções contidas em taes cartas em favor dos naturalizados. Lembra tambem Borges Carneiro o dec. de 1762 e o de 1801, aos quaes eu juntarei o de 2 de Junho de 1762, que se vê na Collecção Delgado. Nessas fontes, a naturalização, ainda quando collectiva, como a concedida pelo $\mathrm{D}$. de 2 de Junho de 1762, tinha sempre caracter de favor, e não era um direito firmado nòs preceitos da lei. $\mathrm{O}$ jus sanguinis era o criterio para a determinação da nacionalidade do individuo no systema das leis portuguesas, que continuaram a orientação das Ordenações de 1603. Seguindo o rumo opposto ao das leis portuguesas, adoptou nassa Contituição Imperial o jus soli para criterio da nacionalidade. Quão acertado foi, do ponto de vista politico, tomar nossa Constituição este alvitre faz sentir, em seus commentarios, Rodrigues de Souza, lembrando que Roma, desejosa de ver augmentado o número de seus cidadãos, concedeu a cidadania a quantos nascessem de ventre livre em seu territorio, e aos estrangeiros que viessem nelle se estabelecer. O mesmo fez Athenas (R. de Souza, V. I. p. 42). Pimenta Bueno porém, inbuido nos principios geralmente acceitos na Europa, a esse tempo, viu na rota seguida por nossa antiga Constituição um regresso ao feudalismo, qualquer coisa semelhante á servidão da gleba (ns. 622 e segs.). Devemos lembrar que a Constituição admittia a obtenção da cida. dania não só pelo nascimento no territorio brasileiro (art. $6 \S 1$ ), mas tambem pelo estabelecimento no Brasil ( $\$ 2$ ), pela residencia pela adhesão á independencia brasileira, e pela naturalização ( $\$ 5$ ). E' tambem de referir que o $\$ 1$ do art. 6 de nossa antiga Constituição provocou muitas reclamações das nações estrangeiras, e que houve certa condescendencia de nossa parte com o D. 1096 de 10 de Septembro de 1860, mandando applicar aos individuos nasci- 
dos no Imperio de paes estrangeiros o Direito da patria de seus paes durante a menoridade (R. de Souza, V. I, pags. 43 e 44). O que mais nos interessa porém é a naturalização.

6) A naturalização, assumpto importantissimo para uma nação nova, em que grande era, e ainda continúa a ser, o número de immigrantes, foi objecto de particular attenção de nosso legislador. Já a lei de 23 de Outubro de 1832 fixava as condições para a obtenção da naturalização, o que equivalia reconhecer a este instituto o caracter moderno, pois assim reconhecia o preceito legal direito a qualquer de impetrar a cidadania, que deixava de ser um favor, como o fôra no regime antigo. O D. 291 de 30 de Agosto de 1843 reduziu a 2 annos a residencia exigida pelo art. $1 \& 4$ da lei que acaba de ser citada. Preoccupou continuamente ao Governo Imperial a naturalização dos immigrantes ou colonos, e, entre os actos relativos a tal assumpto, pode ser destacada a Resolução de 23 de Junho de 1855. Tal era o númeró de actos legislativos sobre nacionalidade e naturalização que, a 14 de Janeiro de 1893, o Ministro da Justiça e Negocios do Interior, respondendo ao aviso n. 6066 do Ministro das Relações Exteriores, dava uma lista e uma cópia de todas as leis e decretos concernentes á matéria. $O$ intuito era servir á legação britannica, e, por este motivo, o Ministro compendiava o que lhe parecia mais importante no referente ao assumpto, e apresentava noticia de alguns avisos de maior interesse. Emfim reportava-se aos relatorios do Ministerio do Interior de Maio de 1891 e de Abril de 1893. O que fica dicto prova quanta importancia, em nossa patria, tem sido justamente dada a este instituto, um dos mais importantes na vida politica de um povo, onde a immigração representa papel conspicuo. Comquanto seja do maior interesse para todos os que se occupam das coisas patrias saber a attenção dada á naturalização no Brasil, nosso intuito, ao fazer este exame, é mostrar as idéas que têm o legislador brasileiro e os nos- 
sos internacionalistas relativamente aos effeitos da naturalização, coherentes com os principios que seguem em Direito Internacional, parecendo-me inutil dizer, como é bem de ver, e será mostrado em seguida, que ésta coherencia tem suas falhas.

7) Não é these nossa, mas de Rodrigo Octavio, a de terem os internacionalistas patrios soffrido a influencia dos principios adoptados na Europa, quando sustentaram seguir o filho a nacionalidade do pae: "La généralité des auteurs brésiliens, évidemment sous l'influence des principes généraux du droit et des legislations étrangères, a soutenu l'opinion affirmative". Menciona Pimenta Bueno, Gama Lobo, Lafayette e João Monteiro. Como acima ficou dicto, ninguem mais andentemente impugnou o jus soli do que Pimenta Bueno, e portanto era de esperar fosse partidario do effeito collectivo: "Dá-se a razão da unidade da familia, e o principio de que o filho, emquanto menor, não tem outra vontade senão a do pae, nem outro domicilio (n. ${ }^{\circ}$ 57)." Quanto a Laffayette, engano parece haver da parte de R. Octavio. Lafayette muito claramente diz: "A mudança de nacionalidade do pae ou da mãe posterior ao nascimento do filho, não exerce influencia sobre a nacionalidade do filho anteriormente constituida" (§ 136). Muito digno de menção é que Lafayette, do mesmo modo que Hall, cuja opinião é por elle citada em nota, não liga sua solução negativa dada á these de que estamos a occupar-nos á consideração da necessidade de se manter o vinculo de familia, melhor assegurado pelo principio pessoal, mas inspira-se no principio da soberania, transcrevendo as palavras de Hall: "The latter doctrine (a child retains his nationality of birth, nothwithstanding that the nationality of his father is changed) is a strict but reasonable deduction from the principle of sovereignty" (P. 11, Chap. V. pag. 238). Ainda como sendo razão de decidir essas complicadissimas questões de effeito da naturalização nos membros da familia, tem por 
vezes apparecido o patriotismo, bem ou mal entendido, conforme se vê em Dalloz, vrs. Droits civils et politiques, S. 2 art. 1, ns. 13 e 14, onde é citada a opinião de Duranton no mesmo sentido. Tambem o movel do patriotismo foi que levou Rodrigues de Souza a escrever as ardentes palavras que se acham á pag. 44 do V. I. de seus commentarios ao art. $6 \S 1$ de nossa antiga Constituição. Por muito louvaver e digno de ser animado que julguemos o sentimento de patriotismo, entretanto parece que elle deve representar um papel secundario, quando tractamos de aplainar difficuldades nas relações pacificas entre os povos. Quando assim procedemos, não fica bem clamar, com Duranton, no presupposto da superioridade da França sobre os demais povos. Parece, pelo contrário, dever nos animar, no estudo destas questões, um espirito de fraternidade que lhes facilitará a solução.

Deveria eu agora entrar a expor os argumentos que se têm apresentado em favor de cada uma das soluções da difficuldade ora estudada. Antes porém verei como tem sido solvida noutros systemas juridico, e, só depois desse estudo, determinarei qual a resposta á pergunta da Faculdade, já em face do Direito a constituir, já em face da lei brasileira.

8) Hall ensina que variam as legislações sobre os effeitos da naturalização do pae relativamente aos filhos nascidos antes dessa naturalização, e ainda menores ao tempo em que foi ella concedida. As leis da Suissa e dos Estados Unidos determinam que o filho do estrangeiro naturalizado fique naturalizado, si menor, pela naturalização de seu pae. Em outros logares, como em França, o menor retem sua nacionalidade não obstante a naturalização de seu pae. Não é tão exacto isto em relação á França como affirma Hall, segundo vamos ver linhas abaixo. A lei americana porém parece radical a este respeito. Eis como se exprime George Davis: "The citizenship of a dependent is that of his principal or su- 
perior. Hence the citizenship of a child is that of his father, of his mother, if illegitimate" (Elements of Intenational Law, pag. 139). Na Inglaterra, parece contraveridissima a questão, pelo que nos diz Foote, acima citado. Em França, encontramos a matéria tractada em muitas disposições legislativas. Fixa a época moderna a lei de 26 de Junho de 1889. No antigo Direito, os effeitos da naturalização eram não retroactivos, absolutos e individuaes, diz Despagnet: " $3 .^{\circ}$ Enfin ils étaient individuels, c'est à dire qu'ils ne se produisaient que pour le naturalisé lui même et non pour ses enfants mineurs ni pour sa femme placés sous sa puissance."

Sob a lei de 1889 explica o autor que acaba de ser citado ter a naturalização do chefe de familia effeito collectivo, accrescentando porém que "ici plusieurs cas sont à distinguer". Apresenta, em seguinda, as modificações, restricções, que soffre ésta regra. (Dr. Int. Pr. n. ${ }^{\circ} 140$ ) Não interessando descer a essas minucias do Direito Frances, importante me parece fazer lembrar que, comquanto a naturalização do estrangeiro em França tenha effeito collectivo (Despagnet, 1 cit., Foignet, P. I., S. 2, C. I), não succede o mesmo com a do frances no paiz estrangeiro, segundo se conclue dos trabalhos preparatorios da lei de 1889 (Foignet, 1. cit., C. 2 \& 2). Para abreviar o estudo de legislação estrangeiras sobre os effeitos collectivos ou individuaes da naturalização, ha o trabalho de Alvarez, que assim é concebido: "A ésta luz, encontramos tres grupos de legislações:

A naturalização é individual em Portugal, Rumania, Prussia, e Turquia. A naturalização do chefe de familia é collectiva para a Inglaterra, a Allemanha, a AustriaHungria, a Italia, a Suissa, a Bulgaria, a Noruega e o Luxemburgo; na America, para os Estados Unidos, a Columbia, o Mexico e a Venezuela. Combinam os dois systemas, dando grandes facilidades para adquirir a nova 
nacionalidade do pae: a França, a Belgica e a Grecia na Europa; na America, a Argentina.

Os unicos paizes em que a questão não está resolvida são a Hespanha, a Dinamarca e a Suecia."

E' o que se póde dizer em synthese. Assim, por exemplo, não é precisamente exacto que a França dê unicamente facilidade para os filhos dos naturalizados adquirirem a nacionalidade de seu pae. Com effeito, conforme explicam Despagnet, e Foignet, os filhois de pae naturalizado frances, são franceses de pleno Direito, e si, no anno seguinte á sua maioridade, elles declinam tal qualidade, esse repudio de nacionalidade francesa opera retroactivamente á feição de uma condição resolutoria (Foignet, ed. de 1909, pag. 43 e Despagnet, cit. n. ${ }^{\circ}$ 140). Assim tambem, em quadro analogo ao de Alvarez, apresenta Foignet o Brasil dando aos filhos de naturalizados o direito de adquirirem a nacionalidade brasileira, pela simples declaração no anno seguinte á sua maioridade, quando a verdade é que o art. 5 do Reg. a que se refere o Dec. n. ${ }^{\circ} 6948$ de 14 de Maio de 1908 unicamente os dispensa da prova de residencia, obrigando-os á prova dos demais requisitos mencionados no art. 4 , ao tempo em que requererem a naturalização. No final desta dissertação tornaremos a ésta matéria, e então a desenvolveremos. Nossa intenção, neste momento, é só mostrar quão precarios são os resumos de Alvarez e Foignet.

Com o que fica dicto, parece ter sido cabalmente provado que os diversos systemas juridicos têm variado muito sobre o modo de solver a questão, por mais imperfeita que seja a noticia que nos dão os mestres dessas oscil. lações nos diversos regimens juridicos dos varios povos: "A difference of pratice exists with respects to the effects of the naturalization of a father upon children born before his naturalization, but minors at the moment when it is effected" (Hall, pag. 237, P. 2 C. 5, Int. Law). 
9 Passemos a ver o que se tem dicto em favor de cada uma das doutrinas. Não ha falta de argumentadores, nem de roupagem para os argumentos, mas estes são poucos, comquanto, como ficou dicto, se apresentem cheios de ornatos. A unidade da familia exige que o filho tenha a nacionalidade do pae, eis o argumento fundamental da escola que responde pela affirmativa á questão. Em todo o rigor, é o que diz Pimenta Bueno no $n .^{\circ} 57$ do seu Direito Internacional, nos termos que acima transcrevemos $\left(\mathrm{n}^{\circ} 7\right)$. E' ainda a unidade da familia que impressiona Foelix, quando diz: "Ceux des membres de la famille qui se trouvent dans la dépendence légale du chef doivent suivre le sort de celui-ci".

E' o argumento que Laurent, cheio de enthusiasmo, com pompa e ornatos, expõe no n. ${ }^{\circ} 191$ do V. 3 de seu Dr. Civil Int. Faz o grande civilista belga allusão á vontade presumida dos membros da familia de deixar a patria no caso de immigração, mas é a unidade da familia que sempre o occupa, e a lucução cahe-lhe dos bicos da penna por muitas vezes (ns. 196 e 197). Ao discorrer sobre este argumento, vem sempre ao espirito a difficuldade de dar ao filho patria contra sua vontade, e por isto dizem os partidarios do effeito collectivo que o filho, emquanto menor, não tem outra vontade que a do chefe da familia. Mas, reconhecendo a força da difficuldade, diz Laurent: "Peut-être conviendrait-il de laisser la même faculté au mineur, en lui permettant, à sa majorité de choisir sa ,patrie d'origine. Cela concilierait tous les droits" (n. ${ }^{\circ}$ 191). Como é sabido, neste assumpto, é recebido o principio que foi proclamado por Cicero: "Ne quis invitus civitate mutetur, neve in civitate maneat invitus" (Pro Balbo). Grande affinidade tem com este argumento que appella para o principio da unidade da familia, o nascido da consideração das difficuldades resultantes nas relaçōes de familia por ter um dos membros uma nacionalidade, e. outros, outra. 
Si já é difficil dizer quaes os direitos do pae sobre o filho, quando a familia se acha em paiz estrangeiro, cresce o embaraço para o jurista si acha na relação juridica pessoas com diversas nacionalidades. "Une nationalité differente, diz Dalloz, reunindo as duas considerações a que acabamos de fazer allusão, tend plus à diviser qu'à rapprocher un père et son fils: elle complique les relations de l'un avec l'autre" (Rep., vers Dr. Civ.) O argumento porém que mais importante parece é o tirado da necessidade de manter harmonia entre os varios institutos do Direito Internacional, e é a elle que seguramente faz referencia nosso illustre compatriota $R$. Octavio, ao dizer que os autores brasileiros, em sua maioria, inspirados nos principios geraes do Direito e das legislações estrangeiras, optaram pelo effeito collectivo da naturalização.

$E^{\prime}$ evidente que o notavel internacionalista patrio fazia allusão á differença que ha entre a lei patria que segue o principio do jus soli, e as estrangeiras que seguem o jus sanguinis. Com effeito, si o filho segue a nacionalidade do pae, parece logico, que a regra seja applicada ainda quando o pae muda de nacionalidade. Hall, cujas palavras são citadas por Lafayette, diz que a doutrina dos que dizem não ter effeito collectivo a naturalização é mais conforme ao principio da soberania, e a outra (a de effeito individual), mais conveniente. Dada ésta pugna, que não póde ser sinão apparente, oomo bem explica Ihering, ao estudar a technica juridica, é olaro dever-se adoptar a doutrina do effeito collectivo, mais conforme ao nosso modo de ver actual: isto dizemos pondo-nos no ponto de vista de Hall, ou de que esteja fóra de dúvida ser mais vantajoso, mais conveniente dar effeito collectivo á naturalização. Abaixo vamos ver que os interesses americanos, que são os que melhor compecemos, aconselham acceitemos a doutrina do effeito individual. Mas, tornando ao que sustenta Hall, parece-nos querer elle dizer que a naturalização tem um quê de subtracção de um individuo a 
seu soberano, e que só excepcionalmente póde ser admittida. Muita attenção ligam, imbuidos na idéa de que o número de subditos faz a grandeza de uma nação, os soberanos europeus á sangria que a America lhes dá por meio de suas leis sobre naturalização, nas quaes procura facilitar aos immigrantes acquisição de direitos de cidadãos nos paizes do Novo Continente. Deste facto faz exposição minuciosa R. Octavio, ao mencionar o effeito que produziu no espirito dos europeus a naturalização collectiva (que não deve ser confundida com a naturalização singular com effeito collectiva) ou nacionalização de todos os estrangeiros (Hall, pag. 565, R. Octavio, n. ${ }^{\circ}$ 11, Laf. § 138) que se achavam em 1889 no Brasil (Le Dr. Int. Pr., pag. 77). Temos ainda uma prova deste modo de ver dos povos europeus nos factos narrados por Alvarez ás pags. 370 e 371 de sua importante obra "Le Droit Internacional Américain", mencionando 'os protestos da França contra os actos da Argentina e da Venezuela, dando naturalização a cidadãos franceses, que assim ficavam isentos do serviço militar europeu. A taes successos faz tambem referencia R. Octavio á pag. 74 da obra que acima foi citada. Este argumento pois do respeito á soberania tem um duplo aspecto. Dizem as nações européas: "Como me tiram subditos contra sua vontade, ou, ao menos sem serem elles ouvidos?". Foi o que affirmou Durantion (T. I. n. ${ }^{\circ}$ 124), quando escreveu: "Il dépendra donc d'un étranger, de ravir à un enfant la qualité si precieuse de français?" Pensam as nações européas que a naturalização collectiva e o effeito collectivo da naturalização terão por consequencia roubar-lhes a America grande número de soldados, e por isto fazem toda a opposição a esses systemas que enriquecem "os paizes americanos de cidadãos". Como se vê, encarada de um ponto de vista elevado, liga-se a questão á da preferencia a dar ao criterio do sangue ou do solo para reconhecimento da nacionalidade, matéria com que vamos nos occupar como 
sendo prejudicial para respondermos á pergunta. Na: acceitação da doutrina contrária ao effeito collectivo actuou o respeito á soberania do Estado a que pertence o menor ao pedir o pae naturalização.

10) Foi Alvarez quem, com perfeito conhecimento das necessidades dos povos americanos, e excluindo os interesses particulares dos governos europeus, interesses que não são os dos membros das communhões sociaes européas, poz em evidencia quão vantajoso era para os europeus mudados para a America o principio do jus soli, hoje dominante em nosso continente. Estudaremos o Direito na vida real, e não por abstracções, por concepções formadas no gabinete, longe dos factos aos quaes devem ser applicadas as regras juridicas. Como observa Alvarez, e a ésta aguida observação do illustre chileno liga a maior importancia o nosso Rodrigo Octavio, foram os creoulos, isto é, filhos de estrangeiros, nascidos na America que fizeram a independencia dos estados americanos, alé então colonias européas. Neste estado de coisas, de seu interesse era que se firmasse logo, nas constitu ç̃̃es, seu direito, reconhecendo o principio do jus soli. 0 interesse porém da maioria dos cidadãos que iam formar os novos Estados americanos coincidia com os da collectividade. Contra a opinião de que a educação da familia é que fórma o espirito de cidadão, sustenta Alvarez que a influencia do meio é decisiva para a idéa de patria no espirito da creança. Rodrigo Octavio desenvolve este pensa. mento do chileno, assim: "C'est en effet, un fait d'experience historique, que l'homme s'attache d'une façon ferme et durable au sol où il est né et qu'il habite, quelque éducation qu'il reçoive dans la famille ou dehors. Il considère comme ses compatriotes tous ceux qui se trouvent dans les mêmes conditions que lui, et cette identité de situation crée la solidarité d'interêts" (pag. 18). Com alguma reserva, devemos acceitar este argumento dos americanos, que acaba de ser mencionado. E' provavel que 
assim não seja na Europa. E' possivel que, na Europa, a influencia da familia seja maior que a do meio. $\mathrm{Na}$ America, onde Rodrigo Octavio e Alvarez fizeram suas observações, perfeitamente verdadeiro é o principio que proclamam, isto é, mais influe no caracter da creança o meio, do que a origem, a familia. Accrescentaremos que, afastada a America da Europa, separados os que para aqui vem da civilização européa, forçados a seguir outra ordem de idéas, pendem os immigrantes as opiniōes que sobre a vida tinham ao aportar ás raias americanas, e assim é explicada a differença entre o hespanhol e o Argentino, entre o portugues e o brasileiro e entre o ingles e o norteamericanos. A distancia actua sobre as proprias familias de crigem estrangeira, e portanto é claro que os menores soffrerão a dupla influencia do meio e das idéas novas de sua familia. Na America pois o jus soli é vantajosissimo correspandendo ás necessidades dos europeus que para cá se mudam, e ás dos Estados americanos, que muito precisam de cidadãos.

Deste modo, temos o interesse do Estado Americano coincidindo com o interesse do estrangeiro que vem da Europa, motivo assás forte para aconselhar a defesa do jus soli em nosso continente. $\mathrm{O}$ argumento tirado da soberania, ou antes do respeito devido á soberania dos Estados europeus ideado pelo eminente Hall, e acceito pelo nasso grande Lafayette, não parece na altura dos dois grandes luminares. Ao contrário, é, cremos, inspirado em principio antiquado, qual o da absorpção do individuo pelo Estado. Parallelamente temos, ao lado dessa these de não ser possivel tirar a um Estado seus subditos contra a vontade do mesmo Estado, ou sem seu consentimento, a de que o subdito deve obediencia perpetua a seu paiz de origem, ou temos o principio de allegiance. Ora esse principio de allegiance tem perdido sempre sua força, como nos ensina o proprio Hall, quando nos diz que, em 1853, já se affirmava "that the doctrine of inalienable allegiance 
is no doubt attended with great practical difficuties". nosso grande Lafayette é o proprio a dar-nos o mais importante argumento possivel contra a doutrina da impossibilidade da renuncia da nacionalidade, quando expõe a seguinte consideração: "E com effeito para conferirem os direitos de nacional ao estrangeiro, não é costume exigirem os Estados certificado de licença da nação a que o individuo pertence." ( $\$ 137$ ) Hall nos informa de que, discutindo a Inglaterra com a America do Norte sobre o assumpto, Story, Kent e Cushing impugnaram, com vantagem, a doutrina "that no persons can, by any act of their own, without the consentment of the government, put off their allegiance and become aliens" (P. 2, C. 5, pag. 230). Com o actual modo de ver pois relativamente á acção da soberania de um Estado europeu sobre seus subditos, nenhuma razão ha para terem os Estados americanos escrupulo de dar a nacionalidade do paiz americano ao estrangeiro que a quizer, independente do consentimento da nação européa. E, uma vez firmada ésta these, a consequencia logica é que podem os Estados americanos adoptar o jus soli, mais conveniente para elles e para os europeus que para cá vieram, e até dar a esses europeus a cidadania. $\mathrm{E}$, si os Estados americanos vêem que é conveniente para elles e para os individuos vindos da Europa o jus soli, podem reconhecer, como passamos a mostrar, que nenhuma vantagem ha em conceder a naturalização dos estrangeiros com effeito collectivo.

11) Estudemos a matéria como é conveniente, perante a realidade, tendo presentes as necessidades da vida americana, e não por concepçôes abstractas, formadas nos gabinetes, longe do mundo para o qual foi feito o systéma juridico. Si a corrente immigratoria aconselha-nos a facilitar a naturalização, não nos leva porém a dar effeito collectivo á concessão da cidadania. Devemos considerar que, si é certo que o immigrante muda na America de idéas, como acima ficou exposto, tornando-se verdadeira- 
mente americano, tão americano quanto os creoulos de que fala Alvarez, os verdadeiros autores da independencia das antigas colonias, os fundadores das naçōes hispano e luso americanas, não é menos certo que nem sempre vêm acompanhados de sua familia, de sua mulher e de seus filhos. Não é raro que venha só o pae, e succede que venha uma viuva, deixando os outros membros da familia na Europa. Podemos até dizer, em fórmula geral, que, em regra, vêm os fortes, e ficam os fracos. Ora, assim sendo, é claro que o effeito collectivo viria dar a cidadania a quem nunca pisou terra americana, e seria sem nenhum fundamento razoavel. Relativamente ainda aos menores que acompa. nham a familia, alguns não têm as idéas do pae, e tencicnam voltar á velha terra, apenas emancipados. Ainda esn relação a estes, absurdo resultado daria a concessão d:ı cidadania pelo effeito collectivo attribuida á naturalização do chefe. Mas, como póde succeder que alguns desses menores, chegados á maioridade, prefiram adoptar a nacionalidade do paiz americano, é louvavel que este lhes facilite o alcance de tal fim, quiçá limitando-se a exigir delles uma solemne opção, ao attingirem a maioridade. Vamos, em seguida, ver a pequena facilidade concedida pela nossa lei a esses menores emancipados (D. 694 de 14 de Maio de 1908 art. $5 \S 5$ ), quando pretendem adqui. rir a nacionalidade brasileira.

Com energia, mas com extrema clareza, fixa o eminente Zeballos a competencia dos Estados para a determinação da nacionalidade: "Que chaque code exerce son action sur son territoire respectif, et que nos citoyens restent où leur volonté, leur devorir et patriotisme les attachent" (Journal, pag. 21). Entende e affirma que assim como um cidadão argentino, póde, em qualquer tempo, deixar a nacionalidade, e receber a de outro Estado soberano, assim tambem é natural que o menor, aos 18 annos, quando se torna politicamente emancipado, e toma armas em defesa da patria, possa optar pelo paiz 
que the parece considerar sua patria. Assim, com grande elevação de vistas, explica o mestre como se póde harmonizar o principio do jus soli americano com o jus sanguinis europeu: a lei póde impor uma nacionalidade ao menor não emancipado politicamente, mas, si ella não retem nenhum cidadão contra a vontade, dá tambem ao menor, uma vez emancipado, o direito de optar por outra patria que não a que lhe foi imposta durante a menoridade. Tal modo de pôr a questão mostra quão liberal é o espirito do notavel mestre (Journal cit., pag. 35).

Concluo pois, pelo que acabo de expor, que não deve ter effeito collectivo a naturalização do chefe de familia, e que portanto os filhos menores devem continuar com a antiga nacionalidade de seu chefe.

12) Estudarei agora a questão em face da lei patria. Em poucas linhas, com elegante concisão, resolve Rodrigo Octavio a difficuldade. Attende a duas hypothe, ses, sendo a primeira a do nascimento no Brasil, e a segunda a de terem os menores vindo para a nossa patria. "Si os filhos nasceram no Brasil, a questão é resolvida em todos os casos pela applicação do principio do jus soli: são já brasileiros. Si nasceram em paiz estrangeiro, a naturalização brasileira do pae não lhes dará nacionalidade brasileira." Appella o mestre para o D. 6948 de 14 de Maio de 1908. Este decreto, expedido para a execução dos decretos legislativos de 12 de Novembro de 1902 e 1085 de 12 de Dezembro de 1907, claramente estabelece não haver effeito collectivo da naturalização, quando preceitua no art. $5 \$ 5$ que fica dispensado de prova de residencia a filho de estrangeiro naturalizado nascido fóra do Brasil, antes da naturalização do pae". Não se diga que a lei se referia ao filho maior, pois que não só não é de acceitar tal interpretação, por não ter razão de ser um tal favor a pessoa completamente desligada da familia, mas tambem porque, si a lei não distingue, nós não temos direito de fazer essa distincção contrária ao nosso sys- 
tema juridico, visto como, segundo acima mostrei, não está no espirito da legislação brasileira, nem mesmo das demais da Amevica, a naturalização com effeito collectivo. Numa palavra: si queremos que a lei se refira a filhos maiores, nenhum motivo ha para dizer que ella não se refere aos menores, e até parece que se referia exclusivamente aos menores. Tambem não se póde negar que - Poder Executivo tivesse competencia para formular a prescripção citada pelo illustre mestre Rodrigo Octavio, porque não passa ella da reproducção do disposto no art. 5 do decreto de Poder Legislativo n. ${ }^{\circ} 904$ de 12 de Novembro de 1902, em nada opposto á nossa Constituição Fiederal.

Refere-se Zeballos á tolerancia européa relativamente aos individuos a quem a diversidade dos criterios dá duas patrias. Diz que a propria França, a mais rigorosa nos assumptos, tem tido alguma condescendencia. Menciona que tem havido certa oscillação a este proposito, e que, no começo da conflagração, alguns desses individuos foram obrigados a tomar armas, e outros não. E' malicioso na explicação da tolerancia em época de paz: "Cette tolerance des gouvernements s'explique par l'intérêt qu'ils ont à favoriser les voyages de centaines de mille d'enfants européens nés dans le nouveau monde et qui s'abstiennent parfois d'aller depenser leur argent et faire leur éducation dans le pays d'origine de leurs parents, par crainte de l'application des lois sur la nationalité qui les obligent à y accomplir leur temps de service militaire" (Journal, cit. pag. 27).

Em um importante artigo que, sob o titulo "Ciudadania y Naturalizacion", publicou Calideron nos Annaes da Faculdade de Direito de Buenos Aires, cita palavras de Zeballos para mostrar quanta importancia ligavam os europeus a que fosse adoptado o principio do jus sanguinis na America. Refere Zeballos que, durante a missão Albendi, entendia-se que, si o governo do Paraná 
acceitasse o principio do jus sanguinis, todas as nações européas se pronunciariam em favor desse governo, e chamaria a França seus consules que se achavam em Buenos Aires (Annaes, T. 2, Serie 3. ${ }^{\mathrm{a}}$, pag. 105).

\section{CONCLUSÃO:}

Jure constituendo e jure constituto, "não importa a naturalização do pae a do filho menor".

Braz de Sousa Arruda, (Docente da Faculdade de Direito). 